\title{
Percutaneous fine needle aspiration cytology of the pancreas: advantages and pitfalls
}

\author{
G KOCJAN,* J RODE, * W R LEES
}

From the *Department of Histopathology, University College and Middlesex School of Medicine, London, and the Department of Imaging, Middlesex Hospital, London

SUMMARY Fine needle aspiration of the pancreas was performed in 62 patients with radiological suspicion of malignancy. All fine needle aspirates were taken under computed tomography or ultrasound guidance. Fine needle aspirates were positive in 31 of 41 patients with histologically or clinically confirmed pancreatic carcinoma. There were no false positive results. The sensitivity of this method for detecting malignant disease was $86 \%$. Cytology was not able to provide conclusive results of benign conditions. Difficulties were encountered in diagnosing well differentiated carcinoma and neuroendocrine tumours and distinguishing them from reactive epithelium and islet cell hyperplasia, respectively. This resulted in a $12 \cdot 1 \%$ false negative rate. There were no complications in our series. Percutaneous fine needle aspiration proved a reliable method of diagnosing pancreatic carcinoma.

The primary objective of the doctor caring for a patient whose symptoms suggest pancreatic carcinoma should be to establish the diagnosis with a minimum of time, testing, money and suffering. 'The mortality of patients with this disease is $99 \%$ within the first two years. ${ }^{2}$ Early diagnosis remains the only known method of cure. Fine needle aspiration cytology of the pancreas under radiological guidance, ${ }^{3-13}$ or during surgery, ${ }^{14-16}$ has been widely used as a diagnostic method. It is especially useful in diagnosing solid neoplasms which account for over $90 \%$ of pancreatic tumours. ${ }^{16}$

\section{Material and methods}

Fine needle aspirates of the pancreas were taken using a $21 \mathrm{G}$ spinal needle under computed tomography guidance and local (subcutaneous) anaesthesia. The needle was attached to a $20 \mathrm{ml}$ syringe and suction enhanced by using a syringe holder. Aspiration was performed after reaching the desired site by applying repeated suction and by releasing it before the needle was withdrawn from the lesion. This prevented the negative pressure forcing the blood into the syringe. After removing the needle from the patient the needle was detached from the holder and aspirated material was ejected on to glass slides averaging nine smears in each case. Cystic fluids and needle washouts were transported in buffered saline.

The fluids were processed in the cytocentrifuge. All

Accepted for publication 3 November 1988 slides were either air dried or fixed in alcohol and stained by either May-Grünwald-Giemsa or Papanicolaou methods, respectively. Whenever possible, spare slides were kept frozen at $-20^{\circ} \mathrm{C}$ for immunocytochemical analysis. Carcinoembrionic antigen (CEA), neuron specific enolase (NSE), and chromogranin were the antibodies used in a limited number of cases.

\section{Results}

Fine needle aspiration cytology was performed in 62 patients with radiological or clinical evidence of pancreatic mass. Definitive diagnosis of carcinoma from fine needle aspirate smears was made in 31 patients. In 21 patients this was confirmed by the histological core biopsy specimen taken at the same time, and in 10 patients clinically by the rapid progress of the disease. There were no false positive results. Cytology was negative in 17 patients; in seven patients material was inadequate for cytological assessment due to poor cell yield or preservation. In seven patients aspirates were suspicious but not diagnostic. Subsequent histology showed carcinoma in five of the negative and two of the inadequate aspirates. Patients with findings suspicious but not diagnostic of malignancy diagnosed in cytological smears were biopsied. Biopsy specimens showed carcinoma in three cases, were negative in two, inadequate in one and suspicious of malignancy in one case. The overall sensitivity of fine needle aspiration cytology in diagnosing pancreatic carcinoma was $86 \%$, excluding the cases where 
Table Correlation between cytological and histological diagnosis, excluding suspicious and inadequate specimens, with final clinical outcome (Figures in parentheses are cases with clinical or clinical and cytological diagnosis only)

\begin{tabular}{|c|c|c|c|c|c|}
\hline \multirow{2}{*}{$\begin{array}{l}\text { Definitive } \\
\text { diagnosis }\end{array}$} & & \multicolumn{2}{|l|}{ Cytology } & \multicolumn{2}{|l|}{ Histology } \\
\hline & & No of cases & Sensitivity (\%) Specificity (\%) & No of cases & Sensitivity (\%) Specificity $(\%)$ \\
\hline $\begin{array}{l}\text { Benign } \\
\text { Malignant }\end{array}$ & $\begin{array}{l}21(5) \\
41(10)\end{array}$ & $\begin{array}{l}17 \\
31\end{array}$ & 100 & $\begin{array}{l}16 \\
31\end{array}$ & 100 \\
\hline Total & 62 & $48^{*}$ & & $47+$ & \\
\hline
\end{tabular}

* Results exclude seven inadequate and seven suspicious aspirates.

+ Results exclude 11 inadequate and four suspicious biopsies.

diagnosis was suspicious and not diagnostic of malignancy (table).

\section{CYTOLOGICAL FEATURES}

In addition to normal pancreatic cells, fine needle aspirates often contained some of the cells from adjacent anatomical structures. Their features are listed below:

Acinar cells (fig 1): These often appear in clusters with round nuclei and finely granular chromatin pattern. Nucleoli are usually small but can be conspicuous. Cytoplasm is abundant, well outlined, but can often be missing, leaving bare nuclei.

Ductal cells (fig 2): These are of cuboidal type, often in tightly cohesive flat sheets resembling ducts. Cytoplasm can contain secretory vacuoles.
Mesothelial cells: These occur in flat sheets with prominent intercellular spaces. Nuclei are uniform, centrally placed, and often contain nucleolus.

Endothelial cells: Fragments of blood vessels are easily recognisable as elongated cells in parallel lines, often containing red blood cells.

Hepatocytes: These are cuboidal cells, often appearing in flat sheets, have central nucleus, prominent nucleolus and abundant granular cytoplasm containing pigment.

Intestinal epithelium: This often appears as sheets of columnar epithelium showing clear luminal border.

Cytological criteria for the diagnosis of pancreatic carcinoma, ${ }^{17}$ listed in order of relevance, are:

1 Extreme nuclear enlargement with nuclear contour irregularity.

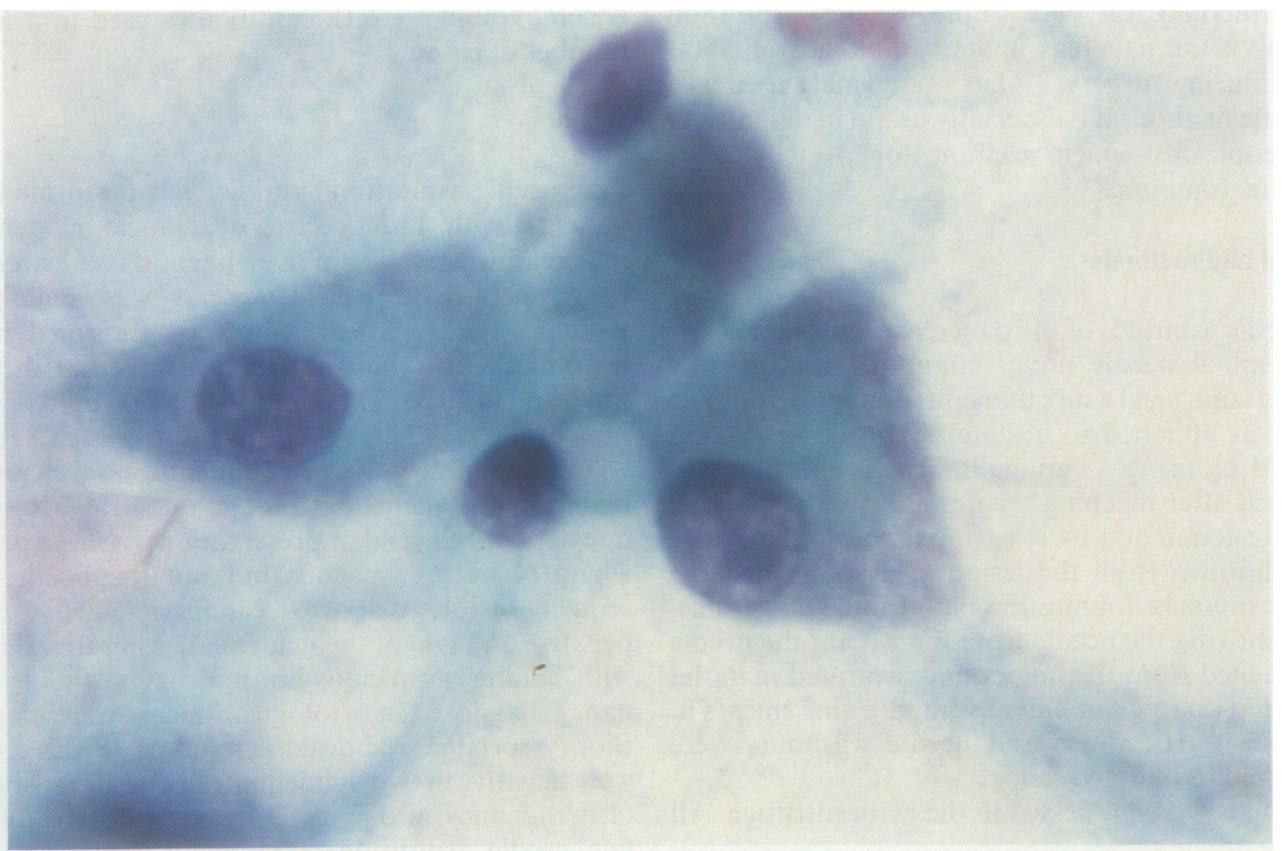

Fig 1 Pancreatic fine needle aspirate smear: acinar cells. (Papanicolaou stain, oil immersion.) 


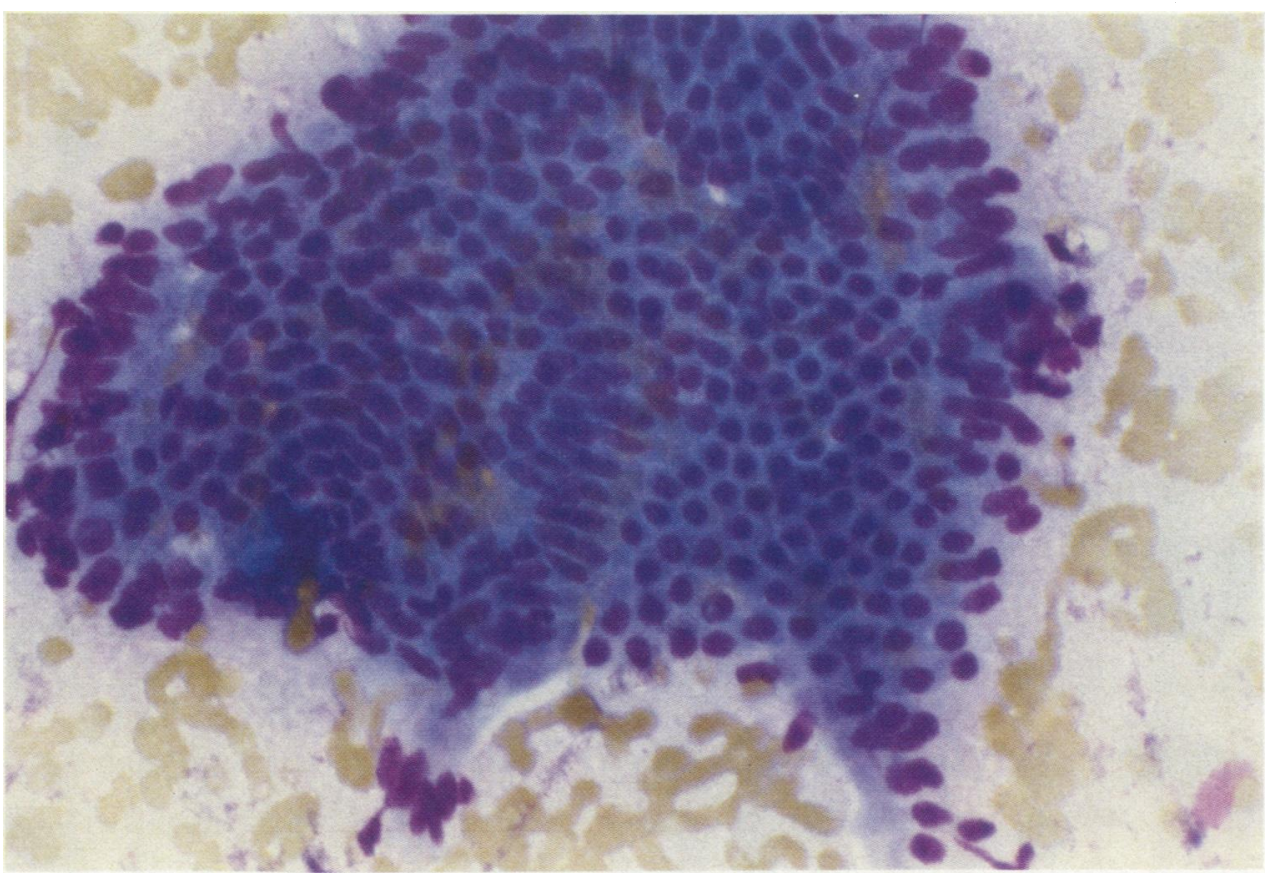

Fig 2 Pancreatic fine needle aspirate smear: duct cells. (May-Grünwald-Giemsa stain.)

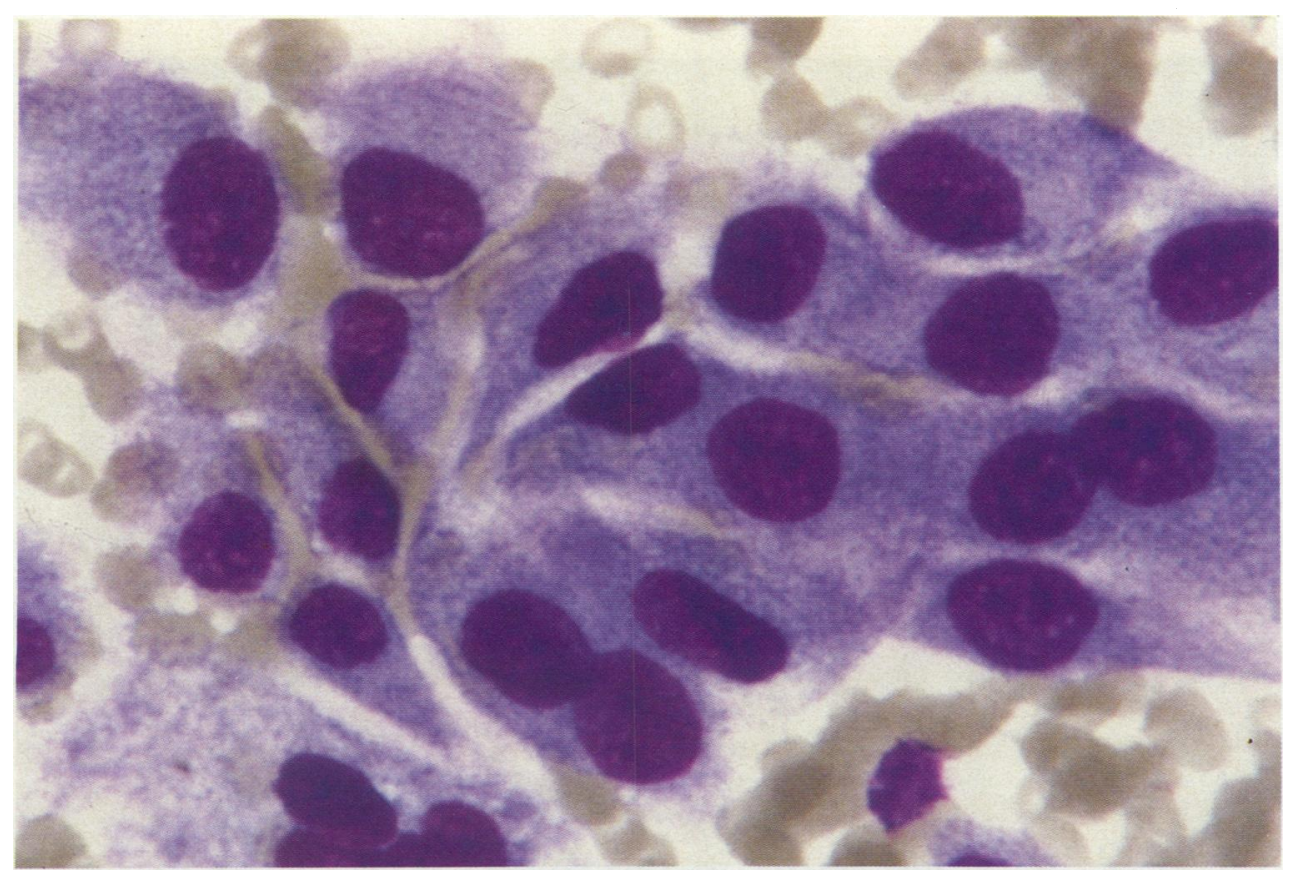

Fig 3 Pancreatic fine needle aspirate smear: well differentiated adenocarcinoma, erroneously interpreted as duct cell atypia. (May-Grünwald-Giemsa.) 


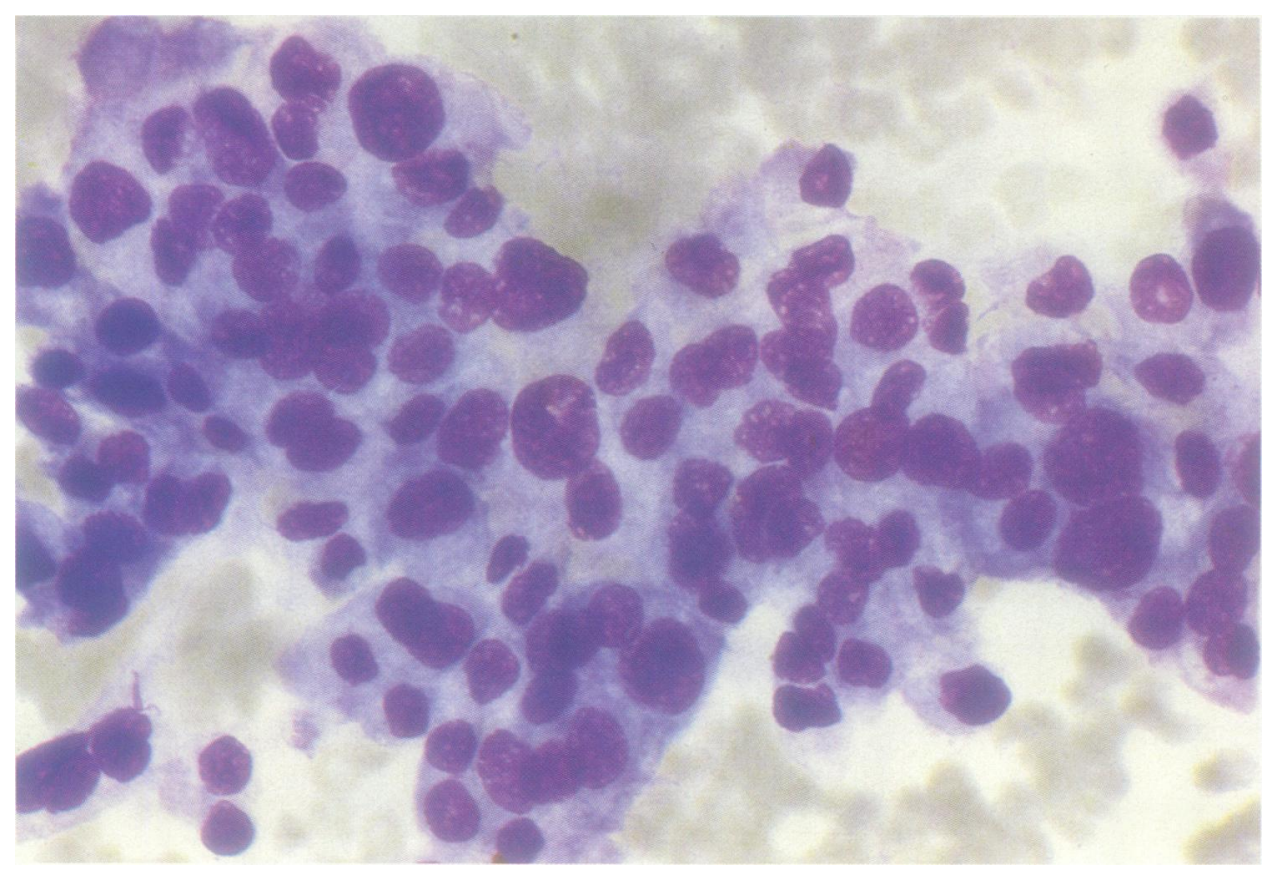

Fig 4 Pancreatic fine needle aspirate smear: poorly differentiated carcinoma showing classic features of malignancy. (May-Grünwald-Giemsa.)

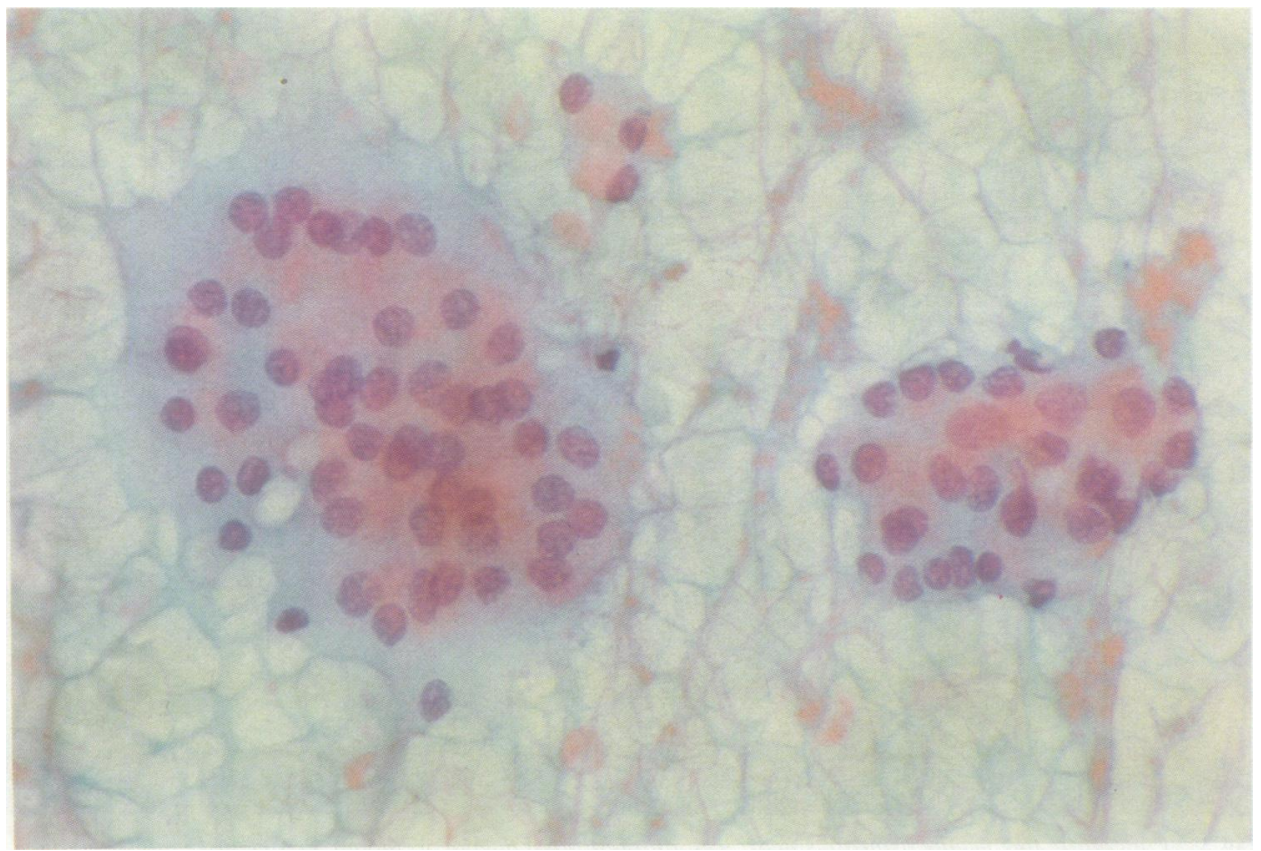

Fig 5 Pancreatic fine needle aspirate: islet cells in islet cell hyperplasia. (Papanicolaou stain.) 


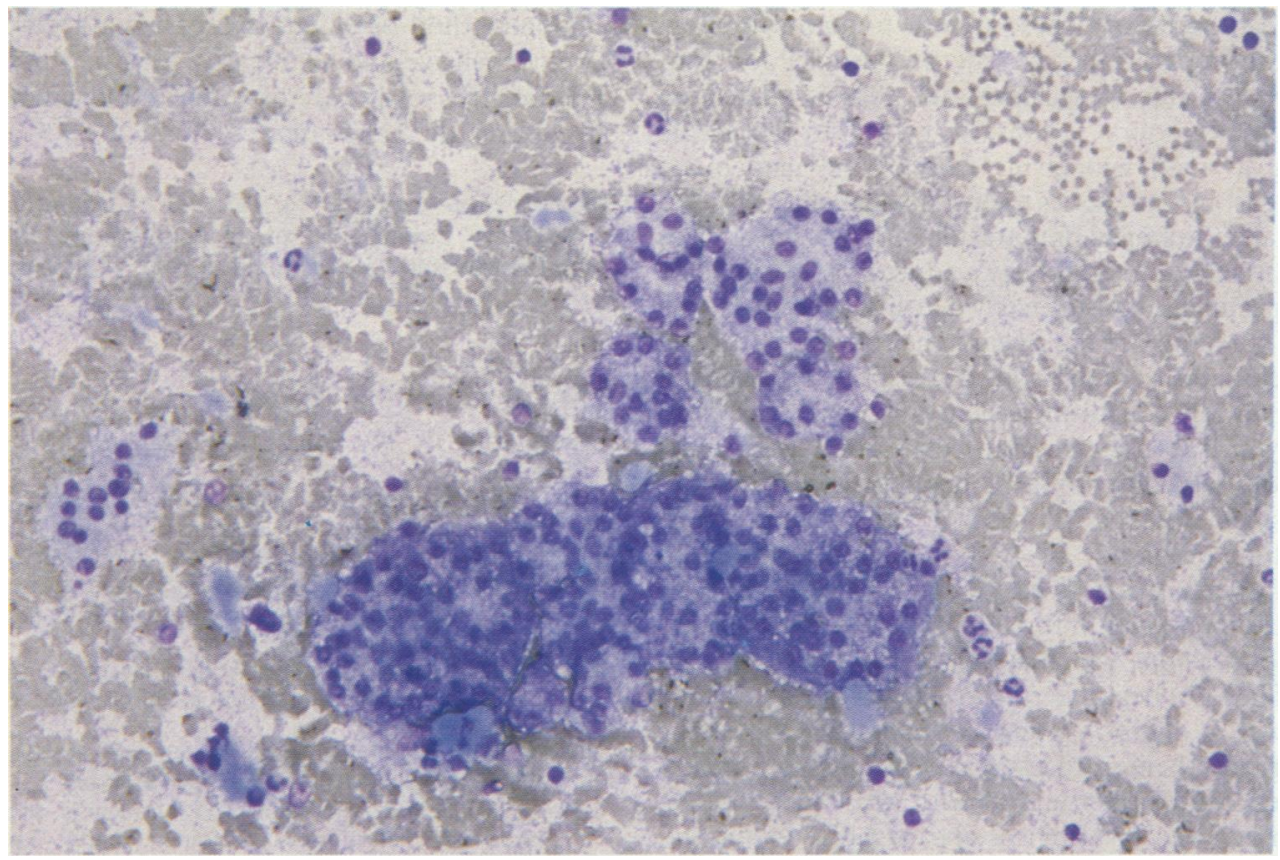

Fig 6 Pancreatic fine needle aspirate smear: islet cell carcinoma (May-Grünwald-Giemsa.)

2 Disoriented or crowded cells in three dimensional groups.

3 Unevenly distributed chromatin.

4 Anisonucleosis.

5 Raised nucleus: cytoplasm ratio.

6 Prominent nucleoli.

Cell typing of malignancies seen in fine needle aspiration smears showed all to be adenocarcinomas. It was usually possible to categorise these according to the degree of differentiation into well, moderately, and poorly differentiated adenocarcinomas (figs 3 and 4). One tumour was classified as mucinous cystadenocarcinoma. One of the cytologically negative smears was a metastasising islet cell tumour, interpreted as islet cell hyperplasia (figs 5 and 6 ).

Immunocytochemistry (APAAP) was performed in a few cases where not all smears were used for routine staining. Difficulties were encountered with strong background staining on the smears. Similarly, heavy admixture of blood often prevented recognition of the relevant cells in the immunostained preparations. As material was usually received both fixed in alcohol and unfixed we were left with the limited choice of the optimal (unfixed) material. The best results were obtained from cell solutions where cells were washed and cytospin preparations resulted in considerably less background staining.

Most of the carcinomas showed strong cytoplasmic CEA positivity. Normal pancreatic ducts and intes- tinal epithelium, however, showed similar but weaker staining. We did not use immunocytochemistry as a distinguishing criterion between benign and malignant lesions. Some of the smears from tumours that showed histological evidence of neuroendocrine differentiation were destained and stained for NSE and chromogranin. The results were not satisfactory due to poor preservation of antigen in destained smears.

\section{Discussion}

The main role of fine needle aspiration cytology of the pancreas is in differentiating benign from malignant conditions. The method has been proved reliable ${ }^{31018-21}$ and safe. ${ }^{22-26}$ In a series of more than 3000 fine needle aspirates Kline et al experienced no complications. ${ }^{22}$ Similar experience was also described by $\mathrm{Ho}$ in a series of 1500 fine needle aspirates ${ }^{23}$ and in reports by Holm et al,,$^{24}$ Zajicek, ${ }^{25}$ and Engzell et a ${ }^{26}$ on several hundred patients with malignant tumours.

Recent advances in imaging techniques have improved the methods of localisation of these tumours. ${ }^{27}$ The sensitivity of the method in diagnosing malignant disease of the pancreas varied in the reported series from $50-86 \% .{ }^{28-38}$ In the present series we found sensitivity of fine needle aspiration to be $86 \%$, disregarding suspicious results.

In our experience the main limitations of fine needle aspiration cytology of the pancreas are: 
False negative results These are due to poor sampling, technical preparation, and interpretation. Poor sampling can be due to scarring and fibrosis associated with some tumours. It can also be due to the needle missing a small neoplasm. Two of the inadequate specimens in our series were subsequently proved malignant. Technical preparation of direct smears was difficult because of the heavy admixture of blood in most specimens, causing early clotting and preventing proper spreading of the smear. The cells were trapped in the clot and were difficult to interpret. Problems of interpretation can occur when distinguishing epithelial atypia due to chronic pancreatitis or duct obstruction from well differentiated neoplasms, particularly when smears are poorly cellular and contain a high admixture of blood. Five of the cases reported as benign or reactive proved malignant (fig 3). Similar difficulties were met in three of the seven cytologically suspicious lesions which subsequently proved malignant. The false negative rate in our series was $12 \cdot 1 \%$. Diagnosis of neuroendocrine cell tumours One of the cytologically benign cases in our series was a malignant neuroendocrine tumour with subsequent matastases in the liver. Cytological smears showed remarkably uniform islet cells in aggregates (fig 6). As these are sometimes seen in islet cell hyperplasia (fig 5) accompanying chronic pancreatitis, they were interpreted as benign. The experience of some authors shows that cell morphology alone is sometimes sufficient for diagnosing these tumours. ${ }^{39} 40$

Differentiation of cell type Most of the tumours in this series were adenocarcinomas, showing various degrees of differentiation. Cytologically we were able to classify one of the tumours as mucinous cystadenocarcinoma. It was not possible, however, to detect foci of neuroendocrine differentiation within individual tumours and report with confidence tumours showing histologically two components (adenosquamous carcinoma). Whether the separation of these histological types will eventually prove relevant to some epidemiological clinical types, clinical feature, or to a response to a specific chemotherapeutic regimen is not known.'

The most important question to be answered by fine needle aspiration cytology is whether a carcinoma is present or not. Using the criteria described by Mitchell et $a l,{ }^{17}$ we feel that extreme nuclear enlargement and disoriented cells in three dimensional clusters are the most helpful features for distinguishing between benign and malignant lesions, regardless of the quantity of cells and presence of other features described by the same authors. In this respect aspiration cytology is a reliable method on which to base a decision to proceed with radical operation in selected cases, as well as prognosis in inoperable cases.

Fine needle aspiration cytology is a quick, safe, and reliable method of diagnosing pancreatic carcinoma. It is inexpensive and is an easily tolerated procedure. Only positive results are of value and negative results do not exclude malignancy.

Requests for reprints to: Dr G Kocjan, Cytology Laboratory, Department of Histopathology, Middlesex Hospital, Mortimer Street, London WIP 7PN, England.

\section{References}

1 Malagelada JR. Pancreatic cancer. Mayo Clin Proc 1979;54: 459-67.

2 Hovdenak N, Lees WR, Pereira J, Beilby JOW, Cotton PB. Ultrasound guided percutaneous fine needle aspiration cytology in pancreatic cancer. Br Med J 1982;285:284-5.

3 Hastrup J, Thommesen P, Fredriksen P. Pancreatitis and pancreatic cancer diagnosed by preoperative fine needle aspiration biopsy. Acta Cytol 1978;21:731-4.

4 Hidvegi D, Nieman HL, James W. Percutaneous transperitoneal aspiration of pancreas guided by ultrasound. Acta Cytol 1979;23:181-4.

5 Ihse I, Isaksson G. Preoperative and operative diagnosis of pancreatic cancer. World J Surg 1984;8:846-53.

6 Kolins M, Bernacki EG, Schwab R. Diagnosis of pancreatic lesions by percutaneous aspiration biopsy. Acta Cytol 1981;25:675-7.

7 Luning M, Kursawa R, Schopke W, et al. CT guided percutaneous fine needle biopsy of the pancreas. Eur J Radiol 1985;20: 221-38.

8 Nguyen GK. Percutaneous fine needle aspiration cytology of the pancreas. Pathol Annu 1985;20:221-38.

9 Phillips VM, Hersch T, Erwin BC, et al. Percutaneous biopsy of pancreatic masses. J Clin Gastroenterol 1985;7:506-10.

10 Tao LC. Ho CS, McLoughlin MJ, McHattie J. Percutaneous fine needle aspiration biopsy of the pancreas. Acta Cytol 1978;22:215-20.

11 Yamamoto R. Tatsuda M, Noguchi S, et al. Histocytologic diagnosis of pancreatic cancer by percutaneous aspiration biopsy under ultrasonic guidance. Am $J$ Clin Pathol 1985;83:409-14.

12 Bognel C, Rougier P. Leclere J, et al. Fine needle aspiration of the liver and pancreas with ultrasound guidance. Acta Cytol 1988:32:22-6.

13 Ihse I, Toregard B, Akerman M. Intraoperative fine needle aspiration cytology in pancreatic lesions. Ann Surg 1979:190:732-4.

14 Keighley MRB, Moore J. Thomson $H$. The place of fine needle aspiration cytology for the intraoperative diagnosis of pancreatic malignancy. Ann Roy Coll Surg Engl 1984;66:405-8.

15 Smith S, Vogelszang RL. Donovan J, Atlas SW, Gore RM, Weiman HL. Intraoperative sonography of the pancreas. Am J Radiol 1985;144:557-62.

16 Pinto MM, Avila NA. Criscuolo EM. Fine needle aspiration of the pancreas: a five year experience. Acta $C y t o l$ 1988;32:39-42.

17 Mitchell ML, Carney CN. Cytologic criteria for the diagnosis of pancreatic carcinoma. Am J Surg Pathol 1985;83:171-6.

18 An-Foraker SH, Fong Mui KK. Cytodiagnosis of lesions of pancreas and related areas. Acta Cytol 1982;26:815-9.

19 Christofferson OP, Poll P. Perioperative pancreas aspiration biopsies. Acta Pathol Microbiol Scand 1970;212:28-32.

20 Kline TS, Goldstein F, Neal HS. Pancreatic carcinoma, pancreatitis and needle aspiration biopsy. Arch Surg 1974;109: 578-9.

21 Willems JS, Lowhagen T. Aspiration biopsy cytology of the pancreas. Schweiz Med Wochenschr 1980;110:845-58. 
22 Kline TS, Neal HS. Needle aspiration biopsy: critical appraisal. Eight years and 3267 specimens later. JAMA 1978;239:36-9.

23 Ho CS, McLoughlin MJ, McHattie JD, et al. Percutaneous. fine needle aspiration biopsy of the pancreas following endoscopic retrograde cholangiopancreatography. Radiology 1977;125: 351-3.

24 Holm HH, Pedersen JF, Kristensen JK, et al. Ultrasonical guided percutaneous puncture. Radiol Clin North Am 1975;13: 493-503.

25 Zajicek J. Introduction to aspiration biopsy. Clin Cytol 1974;4: $1-211$.

26 Engzell U, Esposti PL, Rubio C, et al. Investigation on tumour spread in connection with aspiration biopsy. Acta Radiol 1971;11:385-98.

27 Hall-Craggs MA, Lees WR. Fine needle aspiration biopsy: pancreatic and biliary tumours. Ann J Radiol 1986;147: 399-403.

28 Alpern GA, Dekker A. Fine needle aspiration cytology of the pancreas: An analysis of its use in 52 patients. Acta Cytol 1985;29:873-8.

29 Droese M, Altmannsberger M, Kehl A, et al. Ultrasound guided percutaneous fine needle aspiration biopsy of abdominal and retroperitoneal masses: accuracy of cytology in the diagnosis of malignancy, cytologic tumour typing and use of antibodies to intermediate filaments in selected cases. Acta Cytol 1984;18:368-84.

30 Mitty HA, Efremidis SC, Yeh HC. Impact of fine needle biopsy on management of patients with carcinoma of the pancreas. $\mathrm{Am} \mathrm{J}$ Roentgenol 1981;137:1119-21.

32 Zornoza J. Percutaneous needle biopsy. Baltimore: Williams and Wilkins, 1980:102-40.

33 Smith EH, Bartrum RJ, Chang YC, et al. Percutaneous aspiration biopsy of the pancreas under ultrasonic guidance. $N$ Engl $J$ Med 1975;292:825-8.

34 Hancke S, Holm HH, Koch F. Ultrasonically guided percutaneous fine needle biopsy of the pancreas. Surg Gynaecol Obstet 1975; 140:361-4.

35 Tylen U, Arnesjo B, Kindberg LG, Lunderquist A. Percutaneous biopsy guided by angiography. Surg Gynecol Obstet 1976;142:737-9.

36 McLouglin MJ, Ho CS, Langer B, McHattie J, Tao LC. Fine needle aspiration biopsy of malignant lesions in and around pancreas. Cancer 1978;41:2413-9.

37 Goldstein HM, Zornozo J, Wallace S, et al. Percutaneous fine needle aspiration biopsy of pancreatic and other abdominal masses. Radiology 1977;123:319-22.

38 Pilotti S, Rilke F, Claren R, Milella M, Lombardi L. Conclusive diagnosis of hepatic and pancreatic malignancies by fine needle aspiration. Acta Cytol 1988;32:27-38.

39 Bell DA. Cytological features of islet cell tumours. Acta Cytol 1987;31:485-92.

40 Banner BF, Myrent KL, Memoli VA, Gould VE. Neuroendocrine carcinoma of the pancreas diagnosed on fine needle aspiration. A case report. Acta Cytol 1985;29:422-8. 